\title{
Los conocimientos botánicos de Fernando López de Cárdenas, colector del Real Gabinete de Historia Natural en Córdoba (España) en el siglo XVIII
}

\author{
Ángel Montero' ${ }^{1}$ \& Juan A. Devesa ${ }^{2}$ \\ 1 Jardín Botánico de Córdoba. Avda. de Linneo s/n. 14004, Córdoba (España) \\ ${ }^{2}$ Departamento de Botánica, Ecología y Fisiología Vegetal, Facultad de Ciencias, Universidad de Córdoba. Edificio José \\ Celestino Mutis, Campus de Rabanales, Universidad de Córdoba, 14071 Córdoba (España).
}

\section{Correspondencia:}

Ángel Montero.

e-mail:

paleo.amontero@jardinbotanicodecordoba.com

Recibido: 18 junio 2020

Aceptado: 24 julio 2020

Publicado on-line: 15 septiembre 2020

Editado por: Marta Recio Criado

\begin{abstract}
Resumen
Se estudia el conocimiento botánico de Fernando López de Cárdenas, recolector del Real Gabinete de Historia Natural en el último tercio del siglo XVIII en la provincia de Córdoba (España). Se analizan sus escritos sobre el material botánico que colectaba y enviaba al gabinete real, así como los listados de las especies enviadas. También, el inventario que realizó para informar a la corte de las especies arbóreas que se encontraban en Sierra Morena, por si era de interés recolectar fragmentos de madera, semillas, etc.
\end{abstract}

Palabras clave: Recolecciones botánicas, López de Cárdenas, Real Gabinete de Historia Natural, Siglo XVIII, Córdoba, España.

\begin{abstract}
The botanical knowledge of Fernando López de Cárdenas, collector of the Real Cabinet of Natural History in Córdoba (Spain) in the XVIII Century

The botanical knowledge of Fernando López de Cárdenas, collector of the Royal Cabinet of Natural History in the last third of the 18th century in the province of Córdoba (Spain), is studied. His writings on the botanical material that he collected and sent to the royal cabinet are analyzed, as well as the lists of the species sent. Also, the inventory that it carried out to inform the court of the tree species found in Sierra Morena, in case it was of interest to collect wood fragments, seeds, etc.
\end{abstract}

Keywords: Plant collections, López de Cárdenas, Royal Cabinet of Natural History, XVIII Century, Córdoba, Spain.

\section{Introducción}

El Real Gabinete de Historia Natural fue el fruto de los afanes ilustrados de los Borbones. Carlos III fue su creador, aunque ya su hermano Fernando VI y su padre, Felipe $\mathrm{V}$, habían iniciado ese camino.

El Gabinete sigue la tradición de la nobleza europea de acumular y exponer colecciones de objetos naturales que asombran no solo por su rareza, belleza o tamaño, sino también por proceder de otros continentes u océanos, o por su ordenación sistemática. Centrado, sobre todo, en colecciones de animales, fósiles, conchas, plantas y minerales, en él se iniciaron los estudios de estas materias en la corte, pero no de la botánica, que se llevaría a cabo en el Real Jardín Botánico (Barreiro, 1944, 1992; Hernández Pacheco, 1944; Calatayud, 1986, 1988; Añón, 1987; Puerto Sarmiento, 1988; Montero, 2003;
López, 2005; Armada, 2005), aunque sí tuvo desde su inauguración una Sala de Botánica (Sala para el Reino Vegetal), como puede verse en el plano de Diego de Villanueva'.

En 1807 todavía existía una Sala de Botánica², dependencia que también se cita en el libro de Mieg (1818), escrito en 1817, y que ya no aparece en planos de la segunda mitad del XIX. En dicho libro, Mieg explica que en la Sala de Botánica había también esqueletos de mamíferos y defensas de elefante, e incluso hace una observación al final diciendo que mientras el libro estuvo en la censura se habían sustituido "plantas artificiales" (se refiere a plantas desecadas) por animales, por lo que queda claro que la falta de espacio fue en detrimento de la exposición botánica y acabaría entrañando la desaparición de dicha sala y el envío de todos los ejemplares al Real Jardín Botánico. 
Instrucción de colecta y su impacto en Córdoba. López de Cárdenas (1719-1786)

En el año de 1776 el gobierno de Carlos III publicó una ordenanza (Anónimo, 1776) por la cual los cargos al servicio de la corona promoverían las colectas de objetos de historia natural (conchas, rocas, fósiles, animales, plantas, objetos etnológicos y arqueológicos) tanto en la Península e islas como en las colonias, con destino al gabinete real. Tres años después (1779) se emite, desde el Real Jardín Botánico, una instrucción similar, pero solo para plantas vivas y pliegos de herbario. El interés inicial del Real Gabinete era exclusivamente expositivo, mientras que el del Real Jardín Botánico era de estudio y aclimatación de plantas de utilidad médica o farmacéutica.

Uno de los mayores colectores andaluces del Real Gabinete en el último tercio del siglo XVIII fue Fernando José del Carmen López de Cárdenas (Priego de Córdoba, 16 de abril de 1719 - Montoro, 8 de julio de 1786), quien llegó a ser conocido como "el cura de Montoro". López de Cárdenas estudió en el Seminario de Montilla (Córdoba) y fue ordenado sacerdote en Bujalance, en 1743, pueblo también cordobés que dependía administrativamente de Montoro, hasta que se segregó en el siglo XIX. En 1751 fue enviado a Montoro, en donde estuvo vinculado a la Iglesia de San Bartolomé hasta su muerte, en 1786, a los 67 años de edad (Ramírez de las Casas Deza3; Lucena Llamas, 1995, 2001; Montero, 1999).

Aunque por lo general se le cita como un especialista, más parece solo un coleccionista a tenor de su correspondencia y escritos. López de Cárdenas fue académico honorario de la Real Academia de Buenas letras de Sevilla y académico de la Real Academia de la Historia de Madrid, además de un autor prolífico, si bien casi toda su producción permanece inédita. Escribió sobre historia natural y sobre arqueología, dando a conocer las pinturas esquemáticas de Fuencaliente (Nieto, 1984), pero sus trabajos son principalmente sobre orígenes e historia de poblaciones andaluzas a partir de restos epigráficos y numismáticos (Mestre, 1990; Salas Álvarez, 2009; Beltrán Fortes, 2020). El cura de Montoro no fue un erudito, pero sí una persona culta ${ }^{4}$, y él mismo advierte en una carta que: "...yo en la historia de la Naturaleza no soy profesor instruido â fondo segun los principios $y$ methodo de Ciencia; bien es verdad que soy aficionado y curioso; por admirar â Dios en sus obras..." ${ }^{2}$. Efectivamente, tenía mucha curiosidad y entusiasmo por conocer y dar a conocer, hecho que no deja de tener importancia y le hace ser un destacado representante del período ilustrado en esta localidad cordobesa. Precisamente por ello, mantiene una abultada correspondencia con ilustrados, eclesiásticos y nobles, algunos de ellos personalidades de la época, como el padre Enrique Flórez (1702-1773), instructor de los hijos del Rey y asesor de este en cuestiones de Historia Natural, Pedro Franco Dávila (1711-1786), director del Real
Gabinete de Historia Natural, y con algunos de los que fueron ministros de Carlos III en diferentes etapas, como Pablo Jerónimo Grimaldi (1720-1789), marqués de Grimaldi; José de Gálvez (1720-1787), marqués de Sonora; Pedro Rodríguez de Campomanes (1723-1802), conde de Campomanes y José Moñino (1728-1808), conde de Floridablanca, entre otros muchos, con los que mantuvo una relación epistolar, aunque nunca la tuvo con naturalistas. Esto último resulta particularmente curioso si se tiene en cuenta que López de Cárdenas fue un activo recolector de muestras biológicas y geológicas que tenían como destino el Real Gabinete.

\section{López de Cárdenas y la botánica}

Fue Francisco Pedro de Pueyo, intendente de rentas provinciales del Reino de Córdoba quien, por ser conocedor de las actividades de López de Cárdenas, se puso en contacto con él y le pidió que se ocupara en su localidad de recoger ejemplares de Historia Natural para el gabinete real ${ }^{6}$. La aceptación del encargo supuso el inicio, en 1777, de varias campañas, que se prolongarían hasta 1785 , y que propiciarían el envío al Real Gabinete de muestras de plantas, rocas, fósiles y algún animal disecado (Barras de Aragón, 1920), acompañadas a veces de extensos documentos en los que exponía su parecer sobre su origen y utilidad. En el caso de las plantas, cuando en 1778 envía muestras de Pistacia, las acompaña de un documento sobre el terebinto; un envío de varias especies vegetales en 1779, se acompaña de un escrito "historico, phisico, medico, alegorico, y moral sobre los vegetales", que amplía al final con un pequeño epígrafe sobre las plantas venenosas y, por último, un envío de 1782, se acompaña de una disertación "sobre las semillas y sobre los insectos", en el que atribuye a la generación espontánea el origen de aquellos vegetales que no producen semilla y de los insectos asociados a algunas especies.

El interés de López de Cárdenas por la Botánica y por la Historia Natural en general, está muy mediatizado tanto por su marcado cristianismo como por su desconocimiento de los avances de la ciencia. Creía en la generación espontánea y en el Diluvio como origen de los fósiles tierra adentro, y sus principios de clasificación nunca tenían que ver con la anatomía, reproducción u otros caracteres de importancia taxonómica, sino mucho más triviales, como el color, la forma, la dureza, etc., mostrando sobre todo un interés por la botánica claramente utilitarista.

Las colectas botánicas de López de Cárdenas comienzan en 1777, en fechas cercanas a la petición del Intendente de Córdoba, como se deduce de un comentario en carta de mayo de ese año a Fernando José de Velasco ${ }^{7}$, en la que refiere haber estado colectando, entre otras cosas, lino silvestre en Sierra Morena ${ }^{8}$. En carta posterior ${ }^{9}$, de junio de 1777, avisa del envío al Real Gabinete de semillas que dice son de "lino Bisino ô Carbasino", algunas 
de las cuales piensa sembrar en terreno apto. Al director del Real Gabinete, Franco Dávila, le escribe en julio de 1777 citando también la colecta del lino y le dice, además, que le han avisado de que la: "Cornicabra, y el Enebro se cria en estos arroyos la Sabina, y que su madera es en carnada mui propia para embutidos, Laminos $V^{c}$, tengo experimentado que las camas de enebro no crian chinches, ni llegan â ellas otros insectos"11.

En junio de 1778 informa haber encontrado algunas cornicabras ${ }^{12}$ gruesas cerca del pueblo ("en estos peñascares") y haber sacado "tablas de cerca de dos quartas de ancho, sus colores son negro, blanco, y mixto, hai otras rayadas de verde blanco, $y$ negro; pero todas â ecepcion de la blanca, ási que se acepillan, quedan tersas y resplandecientes aun mas que el granadillo, apostando con su dureza"13. La diferente coloración de la madera de los distintos ejemplares de cornicabra le induce a pensar en diferentes especies..., y también afirma que "las raices de este arbol son grandes, y se sacan de ellas tablas, esta madera es mas porosa y abierta, y la misma de que hacen las caxas. La benefician con aceites y charoles para darle la hermosura que vemos" $^{14}$. Este mismo año termina un extenso documento sobre esta especie, que tanto interés le produjo, y que tituló "Discurso phisico, Medico, Historial, y Alegorico, de el Terebintho."'Cuyas utilidades poco conocidas descubre $D^{n}$ Fernando Jph Lopez de Cardenas Academico de las Reales Academias de Sevilla, de Hista de Madrid, y cura de la Villa de Montoro, encargado de la recoleccion de especies de Historia Natural para el Real Gavinete." "Lo ofrece" "A el Rey Nro Sr. (que Dios guarde) con muestras de todas las partes de dicho Arbol."15. En el texto, que comienza explicando el origen del nombre vulgar por la semejanza de sus "bainas ò folliculos" (las agallas) con los cuernos de las cabras, además de describirla profusamente y compararla con el lentisco ${ }^{16}$, afirma que sus utilidades no son bien conocidas, aunque son muchas en medicina y carpintería, y acusa a los médicos de no usarlo como remedio para todo lo que Galeno ${ }^{17}$ y Dioscórides ya dijeron. De su madera refiere que es apta por su dureza, hermosura y colores, y hace comentarios sobre los insectos que producen las agallas en los que refleja su idea sobre la generación espontánea ("Los modernos quieren, $q^{e}$ procedan de semilla, ô huebos, que depositan en sus maderas otros vivientes de la misma especie: Los Aristotelicos recurren â nueva generacion exputrido, sin recurso à vivientes, $q^{e}$ depositen alli sus huevos ò semillas. Lo cierto es que nadie ha visto entrar insectos à desobar à feminar en unas bainas, y todos ven patentemente la salida: todos las miran cerradas en el tpo de su produccion, y abiertas por ellos cuando salen a bolar". "Primeramente de la materia viscosa, humeda, y resinosa $q^{e}$ destilan estas bainas por de dentro se forman unas masillas blancas en forma de pelotoncillos los quales se visten despues de una pelicula, ú hollejo. Dentro de estas generaciones, pasando a chrisalidas, las $q^{e}$ antes eran embriones".
En 1779, López de Cárdenas hace un pequeño inventario de los árboles de Sierra Morena: "Arboles silvestres de Sierra Morena de los que se pueden sacar palos para colocar en el $R^{\prime}$ Gavinete de Historia Natural' (Tabla 1), una relación en la que no obstante incluye algunos arbustos de gran porte e incluso alguna herbácea. Este mismo año, avisa del envío de un documento ("examen historico, physico, y medico reflexiones alegoricas, $y$ morales") que acompañará la próxima remesa de maderas, en el que se refiere a los usos y propiedades de diversas especies vegetales (tamujo, espino prieto, tamarisco, durillo, jara, aliso, almezo y adelfa), que describe profusamente, y que termina con un apartado sobre "los vegetables que producen veneno", en el que menciona la adelfa, el tejo, el acónito o matalobos, la cicuta o cañaeja, el eléboro, el apocino o cinocrambe, el culantro ${ }^{18}$ la sardonia ${ }^{19}$, la mandrágora, la adormidera, la irca, el hongo y el euforbio ${ }^{20}$. En las descripciones que aporta se nota la influencia de Dioscórides (De Materia Medica) ${ }^{21}$, que cita directamente 0 a través de su traductor Laguna ${ }^{22}$, y donde cita también a Teofrasto ${ }^{23}$, Plinio $^{24}$ y Matiolo ${ }^{25}$.

En diciembre de 1782, un nuevo envío de material $^{26}$ se acompaña de un extenso documento que encabeza como "Disertacion. Proemial sobre las semillas, y sobre los insectos"27. Comienza con el epígrafe "Hai muchos vegetables qe no producen semilla y se propagan sin ellas", y aporta ejemplos ya indicados por el Abad de Pluche 28 y por Cayo Plinio, así como otros que hace suyos, como "la Zabila, la yerba Piña, el mimbrón, el espino blanco o cambrón, la caña, el álamo negro y chopo, la espadaña", aportando citas de aquellos y también de San Agustín, Francisco Valles ${ }^{29}$ y Calmet $^{30}$. La idea que propone, siempre fruto de sus observaciones, es que las "semillas" de árboles como el olivo, el granado o la higuera, no pueden alejarse más allá de unos metros, pues ni el aire, los pájaros o el agua pueden trasportarlas... que sí ha visto piñas llevadas por el río, pero que nunca ha visto pinos en la misma ribera.... y que no cree que los pájaros las transporten porque ha visto crecer árboles en torres y edificios en los que las piedras estaban tan juntas que no cabía ni el pico de un pájaro... Por ello, llega a la conclusión que muchas de las especies que habitan en una región no pueden llegar a otras por ser imposible el transporte de sus semillas, y aboga en estos casos a que su presencia se debe a generación espontánea: "luego ai vegetables $q^{e}$. se reproducen sin semilla: siendo suficiente la tierra para producirlas en tales circunstancias con sales $y$ humedades que produzcan vegetables que antes no hubo". Siguiendo a Francisco Valles, termina exponiendo tres tipos de reproducción en las plantas: 1) por semilla (la manzana, el limón, etc.), 2) "por accidente" (los hongos, el musgo) y 3) "por perfección media", incluyendo entre estas aquellas que "naciendo sin semillas, las producen los arboles germinados sin ellas, $y$ despues se propagan por sus mismas semillas" (encinas y coscojas), Un pensamiento similar desarrolla en relación con 
algunos insectos productores de agallas en el álamo negro, alcornoque, roble y quejigo, labiérnago: "Si los insectos madres proveyeran de casa ò nido para procrear y asegurar los ijuelos, y toda su posteridad; en los alcornoques, robles, quegigos, cornicabras, Alamos negros, $y$ Laviernagos proveerian industriosos de estos medios; pero vemos 10 contrario, y que las bolsas, bainas, y agallas corren por cuenta de los arboles que las producen; señal es que esto se hace por un natural mecanismo $y$ providencia soberana y oculta, mediante la qual se hicieron aquellas mansiones para nueba generacion de insectos sin huevos de madre precedente; segun las exigencias de la materia dispuesta de cada uno para determinadas especie". A estas disertaciones sigue en el texto la descripción de muchas otras especies vegetales y de sus agallas ("el durasno, planta sensitiva, oliva, tila o tilon, gayomba, almendro, fresno, agallas de el Roble, agallas de Quexigo, vidarra, mesto, coscoja, pico de cigueña ô Geramo, cardo corredor, cardillo lechar ó tagarnina, cardo blanco, toba, cardo timonero, cardo borrical, cardo hubero, cardo Ares zin, cardo yescoso, cardo de comer, diente de Perro, moca de Pabo y nispolo), y también del basiodiomiceto conocido popularmente como pedo de el Lobo. Probablemente, las últimas recolecciones botánicas de López de Cárdenas tuvieron lugar en el año 1784 o, al menos, no hay constancia escrita de otras. En mayo de 1785 envió a Madrid un último lote de rocas, un año antes de fallecer en la población de Montoro.

Tabla 1. Inventario realizado por López de Cárdenas, en 1779 con el título: "Arboles silvestres de Sierra Morena de los que se pueden sacar palos para colocar en el $R^{\prime}$ Gavinete de Historia natural”. Grafía original. Se comentan algunos taxones para los que se dan denominaciones vulgares antiguas o dudosas, así como la interpretación taxonómica en algunos casos.

Table 1. Inventory made by López de Cárdenas in 1779 with the title: "Arboles silvestres de Sierra Morena de los que se pueden sacar palos para colocar en el $R^{\prime}$ Gavinete de Historia natural". Original spelling. Some taxa for which old or dubious names are given are discussed, as well as the taxonomic interpretation in some cases.

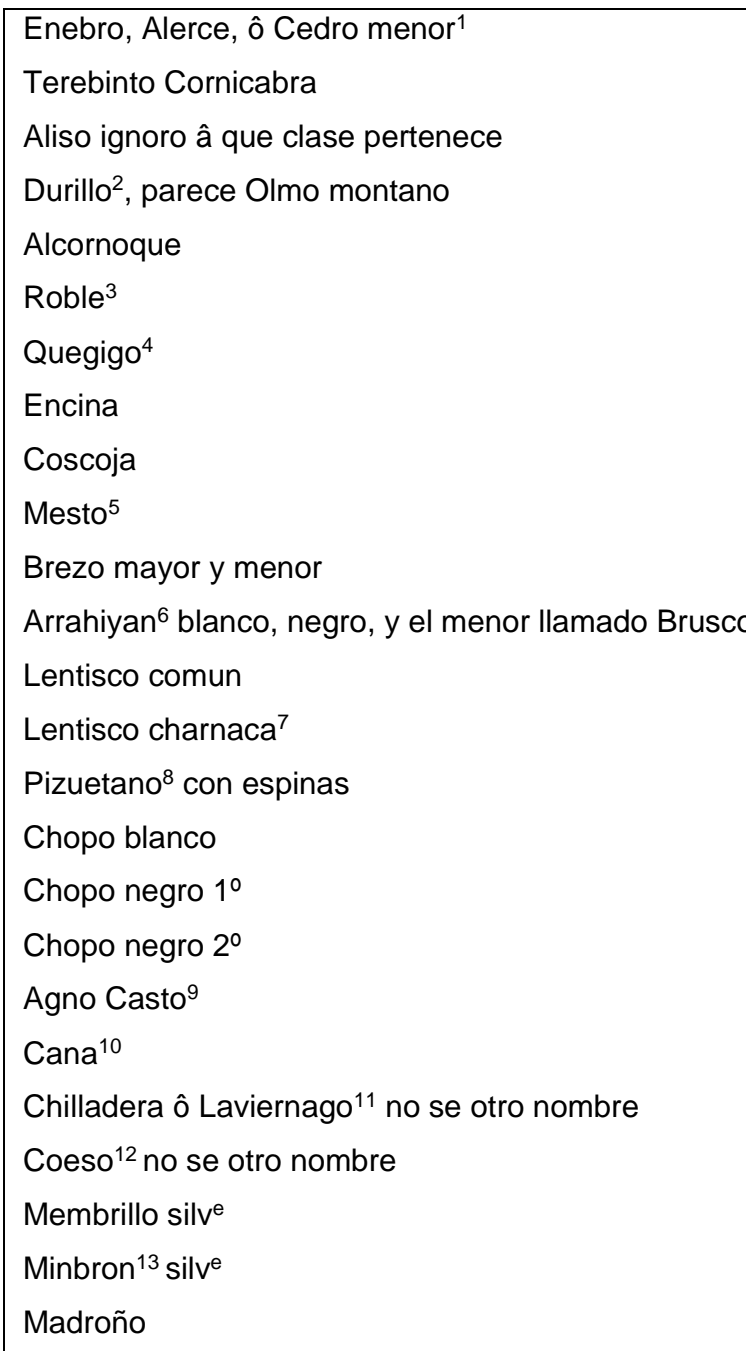

Agracejo ${ }^{14}$ no se otro nombre Almezo

Algarrobo

Tamarisco ${ }^{15}$

Cabrahigo Ligustro ${ }^{16}$ paraiso

Acebuche $^{17}$

Tamujo no se otro nombre

Granado silv.

Azar ${ }^{18}$ no se otro nombre

Piton ${ }^{19}$

Romero

Giniestra Adelfa 20

Pino Real ${ }^{21}$

Pino blanco

Pino doncel

Pino Cipres

Laurel ${ }^{22}$

Castaño ${ }^{23}$

De cañahuecos de campiña:

Mostazo 24

Cañaeja ${ }^{25}$

Pueden ir tambien de los transplant ${ }^{\mathrm{s}}$

Azofaifo

Aromo $^{26}$

${ }^{1}$ Los tres nombres hacen referencia sin duda al enebro. Martínez y Reguera (1916) cita en Montoro Juniperus oxycedrus L., especie relativamente frecuente en la mitad norte de la provincia de Córdoba.

2 Viburnum tinus L., muy frecuente en toda la provincia. 
${ }^{3}$ Probablemente se refiera a Quercus pyrenaica Willd., especie que tiene las hojas lobadas como el roble, y que es relativamente frecuente en el norte de la provincia de Córdoba.

${ }^{4}$ Quegigo o quejigo (Quercus faginea Lam.), muy frecuente en la sierra cordobesa.

${ }^{5}$ Así se conocen los híbridos entre especies del género Quercus. Son relativamente frecuentes en el territorio.

${ }^{6}$ Arrahiyan, arrayán o mirto (Myrtus communis L.).

7 Probablemente se refiera también así al lentisco (Pistacia lentiscus L.), que cita antes, cuando este tiene forma achaparrada y que a veces denominan como charneca.

${ }^{8}$ Pizuetano, piruétano o galapero (Pyrus bourgaeana Decne), muy común en la mitad norte de la provincia de Córdoba.

9 Se refiere al Vitex agnus-castus L., comúnmente llamado agnocasto o sauzgatillo. Disperso por toda la provincia, abundando sobre todo en los cursos de agua.

10 Se refiere a la caña que forma los cañaverales (Arundo donax L.).

11 Phillyrea angustifolia L., muy común en los matorrales de la provincia.

${ }^{12}$ Codeso, escobilla, cambrón, piorno etc., nombre vulgar de varias especies de Adenocarpus. En la provincia de Córdoba solo existe la especie A. telonensis (Loisel.) DC. in Lam. \& DC.

${ }^{13}$ Probablemente se refiere a alguna especie de sauce (Salix sp.). Aunque Martínez Reguera (1916) cita Salix viminalis L. en Montoro, a la que da el nombre vulgar de mimbrera, esta especie solo existe de manera esporádica en la Sierra Subbética, mientras que en la Sierra Morena cordobesa hay otras ocho especies de Salix.

${ }^{14}$ Como agracejos se conocen algunas especies del género Berberis. En la provincia de Córdoba solo existe $B$. hispanica Boiss. \& Reut., pero en las Sierras Subbéticas y no en Sierra Morena, por lo que no se sabe a qué especie se refiere el autor.

${ }_{15}$ Tamarisco es el nombre vulgar que se da a representantes del género Tamarix. Puede referirse a $T$. africana Poir. o T. gallica L., ambas frecuentes en la mitad norte de la provincia de Córdoba.

${ }_{16}$ Ligustro o aligustre. Del género Ligustrum solo se conoce silvestre en la provincia L. vulgare L., en las Sierras Subbéticas. Podría referirse a L. lucidum W. T. Aiton, cultivado a menudo como ornamental.

17 Puede referirse a cultivares asilvestrados de Olea europaea $L$. var. europaea, o a la variedad estrictamente silvestre, $O$. europaea var. sylvestris (Mill.) Lehr., que también se encuentra en el territorio.

18 Con "azar" no puede referirse al naranjo o limonero, no colecta flores, y menos cuando añade que no conoce otro nombre... en un envío de 1784 cita el naranjo y el limonero... Por similitud fonética se puede pensar que se refiera a la popular acerola, fruto del Crataegus, planta frecuente en Sierra Morena. En esta sierra solo está la especie $C$. monogyna L., Ilamado popularmente majuelo, aunque $C$. azarolus L. se cultivaba antiguamente por sus frutos.

19 Se refiere a la pita, Agave americana L., muy extendida ya en el siglo XVIII.

${ }^{20}$ Esta asociación que hace López de Cárdenas es extraña, pues la adelfa (Nerium oleander L.) no tiene relación con la giniesta o hiniesta, nombres vulgares aplicados a especies de los géneros Genista, Cytissus o Retama.

${ }^{21}$ Las citas de pino real, pino blanco y pino doncel pueden corresponder a cualquiera de las especies comunes en el sur de la Península: Pinus pinea L., $P$. pinaster Aiton, y $P$. halepensis Mill. Las tres son frecuentes en la provincia de Córdoba.

22 Martínez Reguera (1916) cita dos especies de laureles en Montoro, la que denomina laurel y cita como Laurus nobilis L., y lo que llama laurel real e identifica con Cerasus lauro-cerasus (L.) Dum. Cours. (Prunus laurocerasus L.). Casi con toda seguridad se refiera a Laurus nobilis L., a menudo cultivado por su interés culinario.

${ }^{23}$ Ya Martínez Reguera (1916) cita Castanea en Montoro. Esta especie no es autóctona en el territorio y solo aparece en esa sierra, esporádicamente, en algunas manchas de origen antrópico para explotación.

${ }^{24}$ Con el nombre de mostazo se hace referencia popularmente a especies de serbal (Sorbus spp.). De ser cierta la identificación, se referiría a $S$. domestica L., cultivada antiguamente por sus frutos.

${ }^{25}$ La cañaeja o cañaheja, nombre vulgar con el que se refiere probablemente a la cicuta (Conium maculatum L.), es frecuente en la sierra cordobesa. En un documento de 1779, sobre plantas venenosas, López de Cárdenas, menciona la "cicuta o cañaeja".

${ }^{26}$ El nombre de aromo está asociado a las acacias (Acacia spp.) en sentido amplio. López de Cárdenas ya comenta que puede venir de transplantes y en un documento posterior (3-diciembre-1782, AMNCN. Ref. 690 de Calatayud, 1987) describe lo que envía, y lo que llama "planta sensitiba", es claramente la Mimosa pudica L., sin duda observada en algún ajardinamiento.

López de Cárdenas fue un hombre culto y un gran coleccionista, claro ejemplo de ilustrado, pero en ningún caso fue un especialista consagrado en ninguno de los campos de las Ciencias Naturales a los que dedicó buena parte de su vida, y ni siquiera cabe referirse a él como un naturalista aficionado. Sus lecturas fueron exclusivamente humanísticas y teológicas, y sus contactos fueron siempre con personajes dedicados a las humanidades o a la política, y no tuvo trato con naturalistas. Sus escritos, pues, son fruto de las observaciones que hizo en sus numerosas exploraciones por las sierras cercanas al objeto de colectar material, lo que le llevó a cometer errores y mantener ideas ya superadas en su época. López de Cárdenas desconocía probablemente las aportaciones que muchos botánicos habían hecho a la flora cordobesa ya desde el siglo XVI, y que no menciona en sus escritos, como Charles l'Ecluse "Clusius" (15261609), Jacques Barrelier (1606-1673), Antonie de Jussieu (1686-1758), Joan Salvador Riera (16831726), Pehr Löfling (1729-1756), Joseph Quer (1695-1764) o Miguel Barnades (1708-1771), entre otros. Sus disertaciones botánicas, pues, aportan un conocimiento muy general y poco científico sobre la flora de la Sierra Morena cordobesa en el último tercio del siglo XVIII, no exento sin embargo de interés cultural y desde el punto de vista etnobotánico.

\section{Agradecimientos}

$A D^{a}$ Mónica Vergés, responsable del archivo del Museo Nacional de Ciencias Naturales, y a D. Manuel Parejo, Ayudante del mismo, por su eficacia en la búsqueda y envío de documentos que han sido 
imprescindibles para la elaboración de este trabajo. También, a los dos revisores anónimos cuyos comentarios han mejorado el texto inicial.

\section{Bibliografía}

Anónimo (1776) Instrucción hecha de orden del Rei N.S. para que los Virreyes, Gobernadores, Corregidores, Alcaldes mayores é Intendentes de Provincias en todos los dominios de S. M. puedan hacer escoger, preparar y enviar á Madrid todas las producciones curiosas de Naturaleza que se encontraran en las Tierras $y$ Pueblos de sus distritos, á fin de que se coloquen en el Real Gabinete de Historia Natural que S. M. ha establecido en esta Corte para beneficio é instrucción pública. 21 págs. Con un estudio preliminar de E. Lemoine Villicaña. Sobretiros del Boletín num. 2 del Archivo General de la Nación (1961), 190-223. México.

Anónimo (1970) Diccionario ilustrado LatinoEspañol. Español-Latino Spes. Editorial Bibliograf, S.A. 7ª edición. Barcelona.

Añón, C. (1987) Real Jardín Botánico de Madrid. Sus Orígenes: 1755-1781. Real Jardín BotánicoC.S.I.C. Madrid.

Armada, J. (2005) Las colecciones de plantas vivas del Real Jardín Botánico. In De San Pío Aladrén, M. P. (Ed.), El Real Jardín Botánico de Madrid (1755-2005). Ciencia, Colección y Escuela (pp.114-132). Madrid. Lunwerg Editores.

Barras de Aragón, F. 1920. La labor de D. Fernando López de Cárdenas, cura de Montoro, como naturalista. Boletín de la Real Academia Sevillana de Buenas Letras, 16, 149-159.

Barreiro, A. J. (1944) El Museo Nacional de Ciencias Naturales. Consejo Superior de Investigaciones Científicas. Madrid.

Barreiro, A. J. (1992) El Museo Nacional de Ciencias Naturales (1771-1935). Ed. Doce Calles. Madrid.

Beltrán Fortes, J. Fernando López de Cárdenas. http://dbe.rah.es/biografias/18297/fernando-joselopez-de-cardenas (09/07/2020)

Calatayud, M.A. (1986) Antecedentes y creación del Real Gabinete de Historia Natural de Madrid. Arbor, CXXIII, 9-31.

Calatayud, M.A. (1987) Catálogo de documentos del Real Gabinete de Historia Natural (1752-1786). Museo Nacional de Ciencias Naturales, CSIC.

Calatayud, M.A. (1988) Pedro Franco Dávila y el Real Gabinete de Historia Natural. Consejo Superior de Investigaciones Científicas. Museo Nacional de Ciencias Naturales. Madrid.

Calatayud, M.A. (2000) Catálogo crítico de los documentos del Real Gabinete de Historia Natural (1787-1815). Monografías, 16. Museo Nacional de Ciencias Naturales, CSIC. Madrid.

Cayo Plinio Segundo, C. (1999) Historia Natural. Edición Facsímil de la versión de F. Hernández \& J. de Huertas. Visor Libros. Universidad Nacional de México. Madrid.
Devesa, J. A. (1987) Linaceae. In Valdés, B., S. Talavera \& E. Fernández Galiano (Eds.), Flora Vascular de Andalucía Occidental (vol. 2, pp. 248-253). Barcelona Ketres.

Dioscórides (2002) Plantas y remedios medicinales (De Materia Medica). Introducción, traducción y notas de Manuela García Valdés. Biblioteca Clásica Gredos. Madrid.

Guido, P. (1612) Racolta breve d'alcune cose piu segualate c'hebbero gli autichi, e d'alcune altre trovate de moderni. Venetia. http://books.google.com/books?id=7jpwZv0LRzk C\&amp;hl=\&amp;source=gbsapi

Hernández-Pacheco, E. (1944) Prólogo. El Museo de Ciencias Naturales y sus naturalistas en los siglos XVIII y XIX. In El Museo Nacional de Ciencias Naturales (pp. 5-81). Consejo Superior de Investigaciones Científicas. Madrid.

López, G. (2005) Desde la creación del Jardín de Migas Calientes (1755) hasta A.J. Cavanilles (1801-1804). In De San Pío Aladrén, M. P. (Ed.), El Real Jardín Botánico de Madrid (1755-2005) (pp.15-27). Madrid. Lunwerg Editores.

López de Toro, J. (1962) Correspondencia entre don José López de Cárdenas y don Fernando José de Velasco. In Homenaje al Profesor Cayetano de Mergelina (pp. 469-511). Murcia. Universidad de Murcia.

Lucena Llamas, J. (1995) Escritores montoreños. Servicio de Publicaciones de la Excma. Diputación Provincial de Córdoba y Excmo. Ayuntamiento de Montoro.

Lucena Llamas, J. (2001) López de Cárdenas: Un prieguense ilustrado afincado en Montoro, autor de dos libros sobre Espejo. Crónica de Córdoba y sus Pueblos. Asociación Provincial Cordobesa de Cronistas Oficiales, VII, 57-80.

Maeder, F. (2008) Sea-Silk in Aquincum: First Production Proof in Antiquity. In: Alfaro, Carmen, and Llilian Karali (eds.), Purpureae Vestes II. Textiles and Dyes in Antiquity, 109-118. Universitat de Valencia.

Maeder, F. (2017) Landscape of sea-silk traces of tradicional production around Mediterranean. https://www.researchgate.net/publication/321943 912. Project Sea-silk Natural History Museum Basel Switzerland. (23/04/2019)

Martínez y Reguera, L. (1916) Reseña HistóricaDescriptiva de la noble, leal y patriótica Ciudad de Montoro. Imprenta La Puritana. Andújar.

Mestre, A. (1990) Correspondencia de los ilustrados andaluces. AMERICA. V Centenario del Descubrimiento. Consejería de Cultura. Junta de Andalucía.

Mieg, J. (1818) Paseo por el Gabinete de Historia Natural de Madrid. Imprenta D. M. de Burgos. Madrid.

Montero, A. (1999) El cordobés Fernando López de Cárdenas, colector del Real Gabinete de Historia Natural en el siglo XVIII. ACMIPA, 38, 20-21.

Montero, A. (2003) La Paleontología y sus colecciones desde el Real Gabinete de Historia Natural al Museo Nacional de Ciencias Naturales. 
Monografías, 19. Museo Nacional de Ciencias Naturales, CSIC. Madrid.

Nieto, G. (1984-5) Don Fernando López de Cárdenas, descubridor del Arte Rupestre Esquemático (1783). ZEPHYRUS, XXXVIIXXXVIII, 211- 16.

Puerto Sarmiento, F.J. (1988) La ilusión quebrada. Botánica, sanidad y política científica en la España ilustrada. Serbal/CSIC.
Ramírez de las Casas Deza, L.M. (s/f) Libro de razón de la genealogía, derechos y pertenencias, honores, empleos y escritos de Dn Fernando Joseph Lopez de Cardenas. Biografía de cordobeses ilustres (obra inédita). Biblioteca Provincial de Córdoba, sección manuscritos. Parte 2a , legajos L-R.

Salas Álvarez, J. (2009) Geografía histórica e historia antigua de Andalucía durante la llustración. HABIS 40, 289-302.

\section{Notas}

1 1773. Archivo de la Real Academia de San Fernando. Madrid.

2 9-abril-1807, Archivo del Museo Nacional de Ciencias Naturales-CSIC, en adelante AMNCN. Ref. 519 de Calatayud (2000).

${ }^{3}$ Manuscrito s/f.

${ }^{4}$ En sus escritos cita a muchos clásicos de diferentes épocas históricas: Estrabón, Teofrasto (lo cita así y como Theofrasto), Dioscórides, Galeno, Plinio, Séneca, Isidoro de Sevilla (lo cita como San Isidoro), Agrícola (lo cita así y como Georgio Agrícola), Feijoo, Torrubia, Tournefort (lo cita así y también como Pitton de Tournefort), Baglivi (lo cita como Baglivo), Agustín de Hipona (lo cita como San Agustín de Trinitate), Dioscórides Anazarbeo, Lemery (lo cita como Lemeri), entre otros muchos y, por supuesto, la Biblia. Y, siempre que puede, hace patente sus conocimientos de latín.

5 10-julio-1777, AMNCN. Ref. 442 de Calatayud (1987).

6 30-mayo-1776, AMNCN. Ref. 296 de Calatayud (1987).

7 25-mayo-1777. [Manuscrito], 108 h. Sig. Mss/2541. Biblioteca Digital Hispanica. Biblioteca Nacional de España. También, publicado en López de Toro (1962).

${ }^{8}$ De acuerdo con Devesa (1987), en la sierra norte cordobesa aparecen silvestres L. bienne Miller, L. tenue Desf., L. trigynum L. y L. strictum L.

9 23-junio-1777. Sig. Mss/2541. Biblioteca Digital Hispanica. Biblioteca Nacional de España. También, publicado en López de Toro (1962), y en AMNCN: 10-julio-1777, Ref. 442 de Calatayud (1987).

${ }^{10}$ El llamado lino bisino o lino carbasino hace referencia a un lino de altísima calidad. La denominación "lino bisino" puede tener dos orígenes: 1) Cayo Plinio en su Hist. Nat. (lib.XIX, cap.I) afirma que el lino de más calidad es el que los griegos llaman asbestino, o de naturaleza que no se puede quemar (de ahí el nombre). Se teje con dificultad porque tiene corta la hebra y resplandece su color en el fuego. Después del lino asbestino, el de más calidad sería el lino bissino. Guido (1612), siguiendo a Plinio, explica que, lo que los griegos llamaban lino abisino o lino asbestino, era para los latinos un lino fino. Teniendo en cuenta lo anterior, lo normal sería pensar que la palabra pudo ir transformándose de la siguiente manera: asbestino-----abisino----bisino, sin embargo, las palabras "byssinus" y "byssus" existen en latín, y el diccionario Latino-Español (Anónimo, 1970) las traduce como lino fino en ambos casos.

2) Por otro lado, lino bisino puede hacer referencia a unas fibras muy delicadas del biso del molusco bivalvo Pinna nobilis L., llamado también "seda de mar" y usado desde antiguo en algunas partes del Mediterráneo para tejer prendas pequeñas y delicadas (ver Maeder, 2008, 2017).

Del lino carbasino, nos dice el diccionario Latino-Español que las palabras "carbaseus" y "carbasus" significan en castellano respectivamente "lino de tela fina" y "lino muy fino, como batista o muselina, o vela de navio o la que tendían tendían en los teatros" (Anónimo, 1970). Plinio (Hist. Nat. lib.XIX, cap.I) menciona, de lino, las velas carbasenas (velas de navío) o toldos para hacer sombra en los teatros o en el foro.

11 10-julio-1777, AMNCN. Ref. 442 de Calatayud (1987).

12 Pistacia terebinthus L. (Anacardiaceae).

13 10-junio-1778, AMNCN. Ref. 510 de Calatayud (1987).

14 20-septiembre-1778, AMNCN. Ref. 527 de Calatayud (1987).

15 9-octubre-1778, AMNCN. Ref. 536 de Calatayud (1987).

16 Pistacia lentiscus L. (Anacardiaceae). Ambas especies son comunes en la Sierra Norte de Córdoba, donde ya habían sido citadas expresamente de los alrededores de Montoro por Martínez y Reguera (1916).

17 Galeno de Pergamo (130-210).

18 Probablemente se refiera al culantrillo de pozo (Adiantum capillus-veneris L.).

${ }^{19}$ Ranunculus spp.

20 9-junio-1779, AMNCN. Ref. 566 de Calatayud (1987).

21 Dioscórides (2002).

22 Andrés Laguna (1513-1559).

${ }^{23}$ Teofrasto (371-287) 
${ }^{24}$ Cayo Plinio Segundo (33-79).

25 Pietro Andrea Gregorio Mattioli (1501-1577), médico y naturalista italiano.

26 13-diciembre-1782, AMNCN. Ref. 690 de Calatayud (1987).

27 3-diciembre-1782, AMNCN. Ref. 690 de Calatayud (1987).

${ }^{28}$ Noël Antoine, Abad de Pluche (1688-1761). Escribió El espectáculo de la Naturaleza (1732).

${ }^{29}$ Francisco Valles (1524-1592). Médico de Felipe II. Escribió sobre medicina y tradujo a Hipócrates y Galeno. Fue un escritor prolífico.

${ }^{30}$ Antoine Agustín Calmet (1672-1757). Escribió varios textos sobre la interpretación de la Biblia. 